\title{
Multi-scale climate modelling over Southern Africa using a variable-resolution global model
}

\author{
FA Engelbrecht ${ }^{1,2 *}$, WA Landman ${ }^{1,3}, \mathrm{CJ}$ Engelbrecht ${ }^{4}, \mathrm{~S}_{\text {Landman }}^{5}$, MM Bopape $^{1}$, B Roux $^{6}$, \\ $\mathrm{JL}$ McGregor ${ }^{7}$ and M Thatcher ${ }^{7}$ \\ ${ }^{1}$ CSIR Natural Resources and the Environment - Climate Studies, Modelling and Environmental Health, Pretoria, 0001, South Africa \\ ${ }^{2}$ Climatology Research Group, GAES, University of the Witwatersrand, South Africa \\ ${ }^{3}$ Department of Geography, Geoinformatics and Meteorology, University of Pretoria, Pretoria, 0002, South Africa \\ ${ }^{4}$ Agricultural Research Council - Institute for Soil, Climate and Water, Pretoria, 0001, South Africa \\ ${ }^{5}$ South African Weather Service, Private Bag X097, Pretoria, 0001, South Africa \\ ${ }^{6}$ Weather and Environmental Prediction, Centre for Australian Weather and Climate Research, Bureau of Meteorology, \\ Melbourne, Australia \\ ${ }^{7}$ Centre for Australian Weather and Climate Research, CSIRO, Aspendale, Australia
}

\begin{abstract}
Evidence is provided of the successful application of a single atmospheric model code at time scales ranging from shortrange weather forecasting through to projections of future climate change, and at spatial scales that vary from relatively low-resolution global simulations, to ultra-high resolution simulations at the micro-scale. The model used for these experiments is a variable-resolution global atmospheric model, the conformal-cubic atmospheric model (CCAM). It is shown that CCAM may be used to obtain plausible projections of future climate change, as well as skilful forecasts at the seasonal and short-range time scales, over the Southern African region. The model is additionally applied for extended simulations of present-day climate at spatial scales ranging from global simulations at relatively low horizontal resolution, to the micro-scale at ultra-high $(1 \mathrm{~km})$ resolution. Applying the atmospheric model at the shorter time scales provides the opportunity to test its physical parameterisation schemes and its response to fundamental forcing mechanisms (e.g. ENSO). The existing skill levels at the shorter time scales enhance the confidence in the model projections of future climate change, whilst the related verification studies indicate opportunities for future model improvement.
\end{abstract}

Keywords: multi-scale climate modelling, variable-resolution atmospheric model

\section{Introduction}

Dynamic climate models have become the primary tools for the projection of future climate change, at both the global and regional scales. Dynamic models are based on the laws of physics applied to the earth system. When stated in mathematical form, the laws constitute a set of complex partial differential equations. The equations in discretized form are solved numerically within dynamic climate models, with processes that cannot be resolved at a given grid resolution described by parameterisation schemes. Projections of future global climate change, such as those described in Assessment Report Four (AR4) of the Inter-Governmental Panel on Climate Change (IPCC), are based on coupled global climate models (CGCMs) that simulate the coupled ocean, atmosphere and land-surface processes. CGCMs are computationally expensive. On present-day super-computers, when used to simulate climate over a period of a century or longer, these models are typically applied at horizontal resolutions of about 100-200 km. However, more detailed simulations are needed for regional climate-change impact studies and to drive application models (e.g. hydrological models applied over small catchments). Dynamic regional climate models (RCMs) are used to obtain such detailed projections. These models

This paper was originally presented at the Water Research Commission 40-Year Celebration Conference, Kempton Park, 31 August - 1 September 2011.

* To whom all correspondence should be addressed.

푤 +27 12841 3942; fax: +27 12841 2597; e-mail: fengelbrecht@csir.co.za are applied at high-resolution over selected areas of interest, and may be forced at their lateral boundaries (in the case of limited-area models) or in the far-field (in the case of variableresolution global models) by the output of a CGCM. Typically, RCMs are atmosphere-only models that are also forced at their lower boundaries by the sea-surface temperature (SST) and sea-ice simulations of a CGCM, and by static descriptions of the land-surface. Present-day computing power allows RCMs to be applied at the continental scale at resolutions of about $50 \mathrm{~km}$, and at even higher resolutions when applied over sub-continental or smaller regions (e.g. Lal et al., 2008; Roux, 2009).

Although the projections of dynamic climate models are being used increasingly to inform climate-change adaptation studies, they are sometimes criticised as not being verifiable, the argument being that it will only be possible to verify the reliability of the projections several decades into the future. In this paper, however, we argue that confidence in projections of future climate change may be enhanced through the application and verification of the models used for climate projection over multiple time- and spatial scales. Indeed, a new generation of climate models is currently under development, which is sufficiently versatile to be applied across the range of time scales relevant to short-range weather forecasting, seasonal forecasting and the projection of future climate change (e.g. Davies et al., 2005). Moreover, these models can be applied at spatial scales ranging from global simulations at resolutions of $100-200 \mathrm{~km}$, to the micro-scale at resolutions as high as 1 km (e.g. Janjic et al., 2001; Davies et al., 2005). Applying a model that is traditionally used for the projection of future climate change for short-range weather 


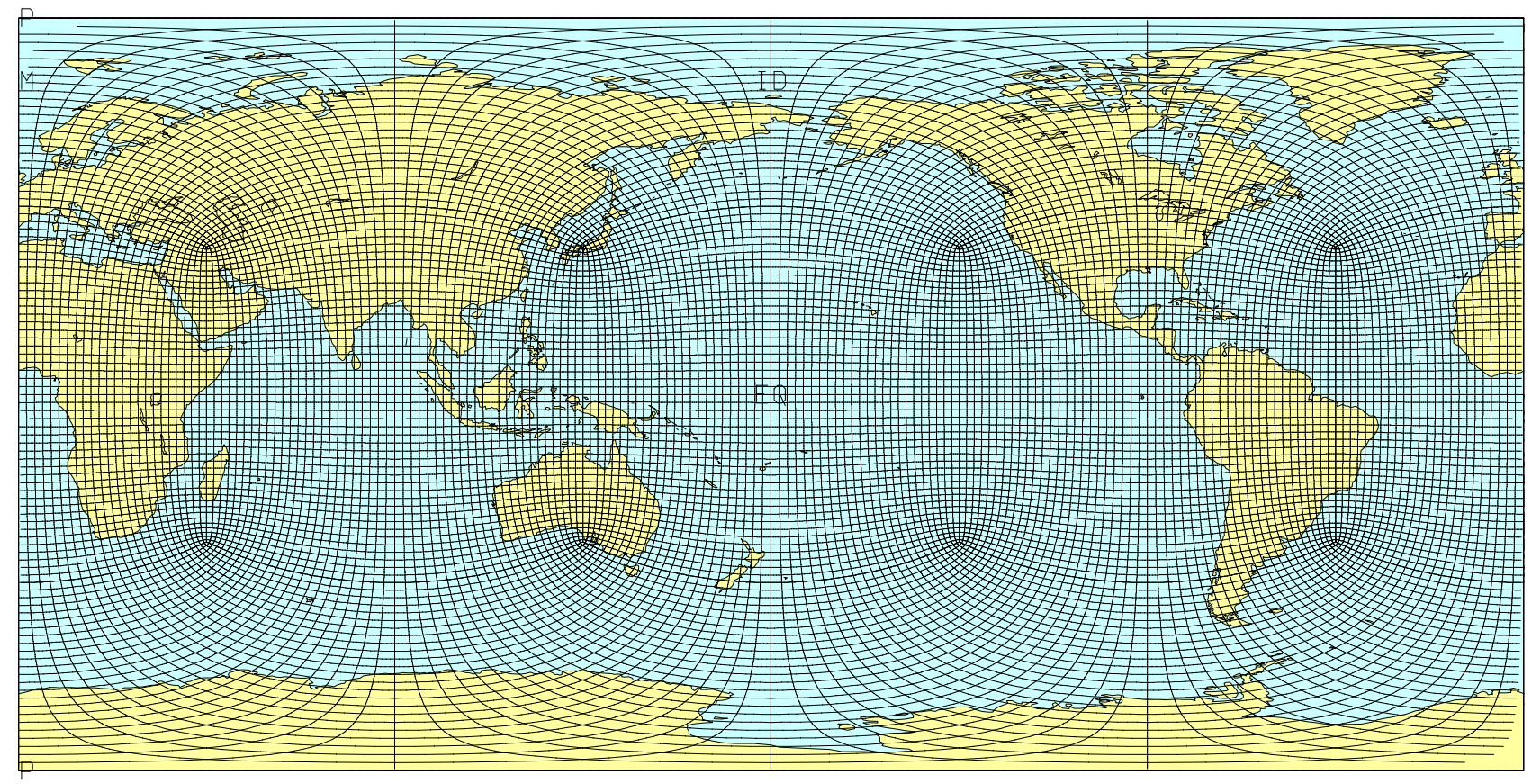

Figure 1

Quasi-uniform C48 conformal-cubic grid (Schmidt factor 1) that provides about $200 \mathrm{~km}$ resolution in the horizontal

forecasting provides the opportunity to regularly test the model's ability to simulate key atmospheric processes such as convection (through the verification of hindcasts and operational forecasts). This is of particular importance within the context of improving the parameterisation schemes that are thought to be a key source of uncertainty in the projections of both global and regional models. Simulations and forecasts at the seasonal time-scale provide the opportunity to verify the climate model's ability to replicate the interannual variability in present-day climate; of key importance here is the model's ability to realistically simulate the attributes of the El Niño Southern Oscillation (ENSO) and the Madden-Julian Oscillation (MJO), the main sources of climate variability at the global scale. Thus, applying a climate model across a range of spatial and time scales provides a stringent test of the physical robustness of its numerical formulation and physical parameterisation schemes. It is sometimes argued that the parameterisation schemes of RCMs are artificially 'tuned' to replicate the climate of a specific area of interest at a given resolution, and that the model projections when applied under different future forcing scenarios are not reliable. However, if the schemes can be shown to function robustly across a range of spatial scales (from the global scale to the micro-scale) and over different climate regimes (from the tropics to the highlatitudes) it greatly increases the confidence in the validity of the schemes under conditions of future anthropogenic forcing

Not many currently existing climate models are versatile enough to be applied across a range of time and spatial scales. In fact, most of the traditionally formulated limited-area RCMs do not have the capability to be used as global models, whilst the majority of global models cannot be applied as RCMs (except for the computationally expensive case of highresolution global runs). Although many of the global models used for the projection of climate change are also applied for seasonal forecasting, few of these models are applied for high-resolution short-range weather forecasting. Variableresolution global models provide perhaps the best framework for performing simulations across a range of spatial and time scales. These models may be applied in stretched-grid mode over selected areas of interest, thereby functioning as RCMs. This approach to regional climate modelling avoids the problems that limited-area models experience with the reflection of atmospheric waves at their lateral boundaries, and provide a more flexible framework for the downscaling of CGCM simulations to high spatial resolution. Alternatively, such models may be applied at quasi-uniform resolution to function as conventional global models. Clearly, the dynamics, numerical formulation and physical parameterisation schemes of variable-resolution models need to be sufficiently versatile to function across a range of length scales and over different regions of the globe.

In this paper, we report on the application of such a variable-resolution global atmospheric model, the conformalcubic atmospheric model (CCAM), across a wide range of spatial and time scales. The ability of the model to provide realistic simulations of present-day climate and plausible projections of future climate change over southern Africa is described. Additionally, the skill of the model in shortrange and seasonal weather forecasting over the region is investigated. By applying the model in stretched-grid mode the versatility of the model dynamics, numerical formulation and physical parameterisations to function across a range of length scales over the southern African region and globally, is explored.

\section{The conformal-cubic atmospheric model}

The variable-resolution global atmospheric model applied in this paper, CCAM, has been developed by the Commonwealth Scientific and Industrial Research Organisation (CSIRO) (McGregor, 1996, 2005a, 2005b; McGregor and Dix, 2001; 2008). It employs a semi-implicit semi-Lagrangian method to solve the hydrostatic primitive equations. The GFDL parameterisations for long-wave and short-wave radiation 


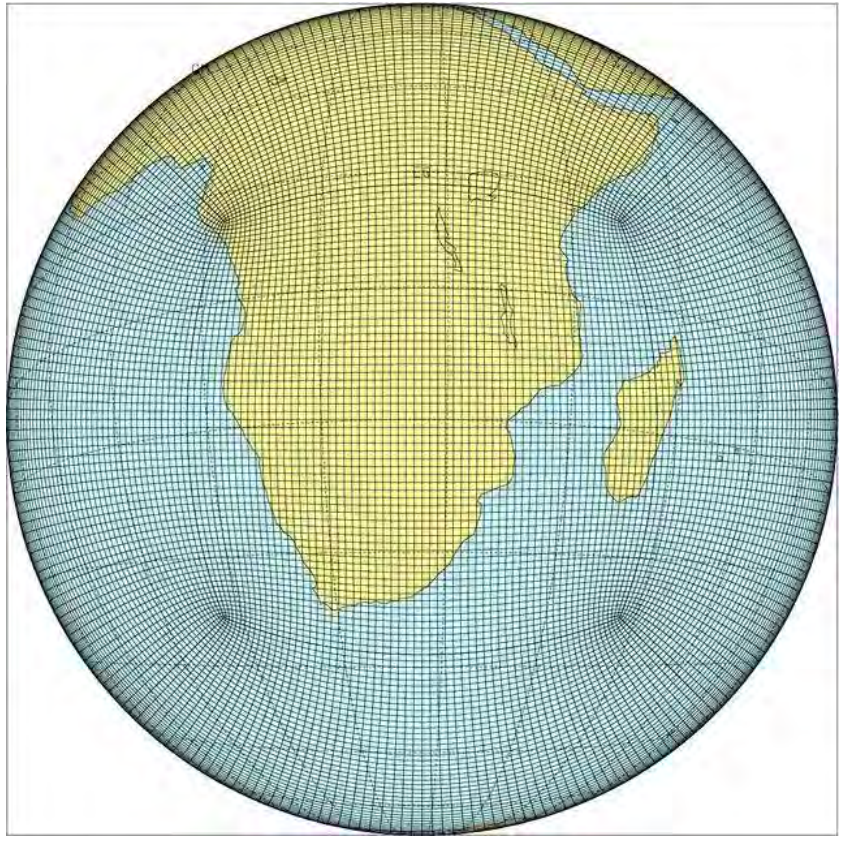

Figure 2

C64 stretched conformal-cubic grid (Schmidt factor 2.5) over Southern Africa and tropical Africa. The resolution is about $60 \mathrm{~km}$ over the area of interest and decreases to about $400 \mathrm{~km}$ in the far-field.

are employed (Lacis and Hansen, 1974; Schwarzkopf and Fels, 1991), with interactive cloud distributions determined by the liquid and ice-water scheme of Rotstayn (1997). A stability-dependent boundary layer scheme based on Monin Obukhov similarity theory is employed (McGregor et al., 1993), together with the non-local treatment of Holtslag and Boville (1993). A canopy scheme is included, as described by Kowalczyk et al. (1994), having 6 layers for soil temperatures, 6 layers for soil moisture (solving Richard's equation) and 3 layers for snow. The cumulus convection scheme uses a mass-flux closure, as described by McGregor (2003), and includes downdrafts, entrainment and detrainment. Gravity wave drag is parameterised following Chouinard et al. (1986).

CCAM may be applied at quasi-uniform resolution, or alternatively in stretched-grid mode to obtain high resolution over an area of interest. Figure 1 shows a C48 quasi-uniform conformal-cubic grid, of about $200 \mathrm{~km}$ resolution in the horizontal. Stretched grids are obtained using the Schmidt transformation. An example of a stretched grid of C64 resolution and a Schmidt factor of 2.5 is provided in Fig. 2. This stretched grid provides about $60 \mathrm{~km}$ resolution over Southern and tropical Africa, with the resolution decreasing to about $400 \mathrm{~km}$ in the far-field. For the high-resolution simulations on stretched grids, a digital filter technique (Thatcher and McGregor, 2009; 2010) may be employed to preserve the large-scale patterns of an earlier performed coarse-resolution CCAM simulation.

\section{Projections of future climate change}

CCAM and its predecessor, the Division of Atmospheric Research Limited-Area Model (DARLAM) of the CSIRO, have been applied in South Africa for the past 10 years to simulate present-day climate and future climate change over Southern Africa and tropical Africa (Engelbrecht et al., 2002;
Engelbrecht, 2005; Olwoch et al., 2008; Engelbrecht et al., 2009; Potgieter, 2009). CCAM has been shown to provide satisfactory simulations of annual rainfall and temperature distributions, as well as of the intra-annual cycle in rainfall and circulation over the region (Engelbrecht, 2005; Engelbrecht et al., 2009). It has also been shown that the model is capable of providing a realistic representation of observed daily climate statistics (e.g. the frequency of occurrence of closed lows, closed-low tracks and extreme rainfall events) over Southern Africa (Potgieter, 2009).

In this paper, we report on a new set of climate projections performed over Southern and tropical Africa using CCAM, to illustrate the capability of the model to function as a flexible downscaling tool at the climate-change time scale. In the downscaling procedure, the sea-ice and bias-corrected SSTs of 6 CGCMs (CSIRO Mk 3.5, GFDL2.1, GFDL2.0, HadCM2, ECHAM5 and Miroc-Medres) from AR4 of the IPCC are first used as lower-boundary forcing in CCAM simulations performed at a quasi-uniform resolution (about $200 \mathrm{~km}$ in the horizontal - see Fig. 1). All the simulations are for the A2 scenario of the Special Report on Emission Scenarios (SRES), and for the period 1961-2100. The SST biases are derived by comparing the simulated and observed present-day climatology of SSTs for 1979-1999 for each month of the year; the same monthly bias corrections are applied for the duration of the simulations (see Katzfey et al. (2009) for more details of this methodology). The strategy of first performing bias correction on the CGCM SSTs before these fields are used for downscaling, addresses a well-known systematic problem in all CGCMs, namely the 'cold tongue' bias along the equatorial Pacific. This bias leads to significant distortions of flow patterns over the equatorial Pacific in the host CGCMs. The bias correction of the host CGCM SSTs allows the quasiuniform CCAM simulations to better capture present-day trade winds and tropical circulations (e.g. Katzfey et al., 2009; McGregor et al., 2011) when forced with the bias-corrected fields. That is, CCAM is forced only at its lower boundary with the bias-corrected CGCM SSTs and sea-ice, and not with CGCM atmospheric circulation fields (the model runs in stand-alone mode - see Engelbrecht et al. (2009)). The second phase in the downscaling procedure involves applying CCAM in stretched-grid mode over Southern and tropical Africa, to obtain simulations of approximately $60 \mathrm{~km}$ resolution (Fig. 2). In these runs, the resolution decreased to about $400 \mathrm{~km}$ in the far-field. All the simulations were performed on the Sun Hybrid System of the Centre for High Performance Computing (CHPC) in South Africa.

The ensemble average of the austral summer (December to February, DJF) simulated rainfall climatology for the period 1961-1990 is compared against observations in Fig. 3. The observations are from the CRU-TS 3.1 data set (Mitchell and Jones, 2005) of the Climatic Research Unit (CRU). CCAM simulates the average position of the Inter Tropical Convergence Zone (ITCZ), and associated rainfall in a zonal band stretching from Angola over Zambia and into Mozambique, very well. Other aspects of the regional distribution of summer rainfall, such as the west-east gradient in rainfall over South Africa, and the relatively dry conditions that occur in a zonal band stretching from Botswana to the Limpopo River basin of South Africa and Zimbabwe, are also well captured in the model simulation. It is evident that the model has a wet bias in representing the average daily summer rainfall totals over most of Southern Africa. Over parts of the eastern escarpment of South Africa and Lesotho, the 

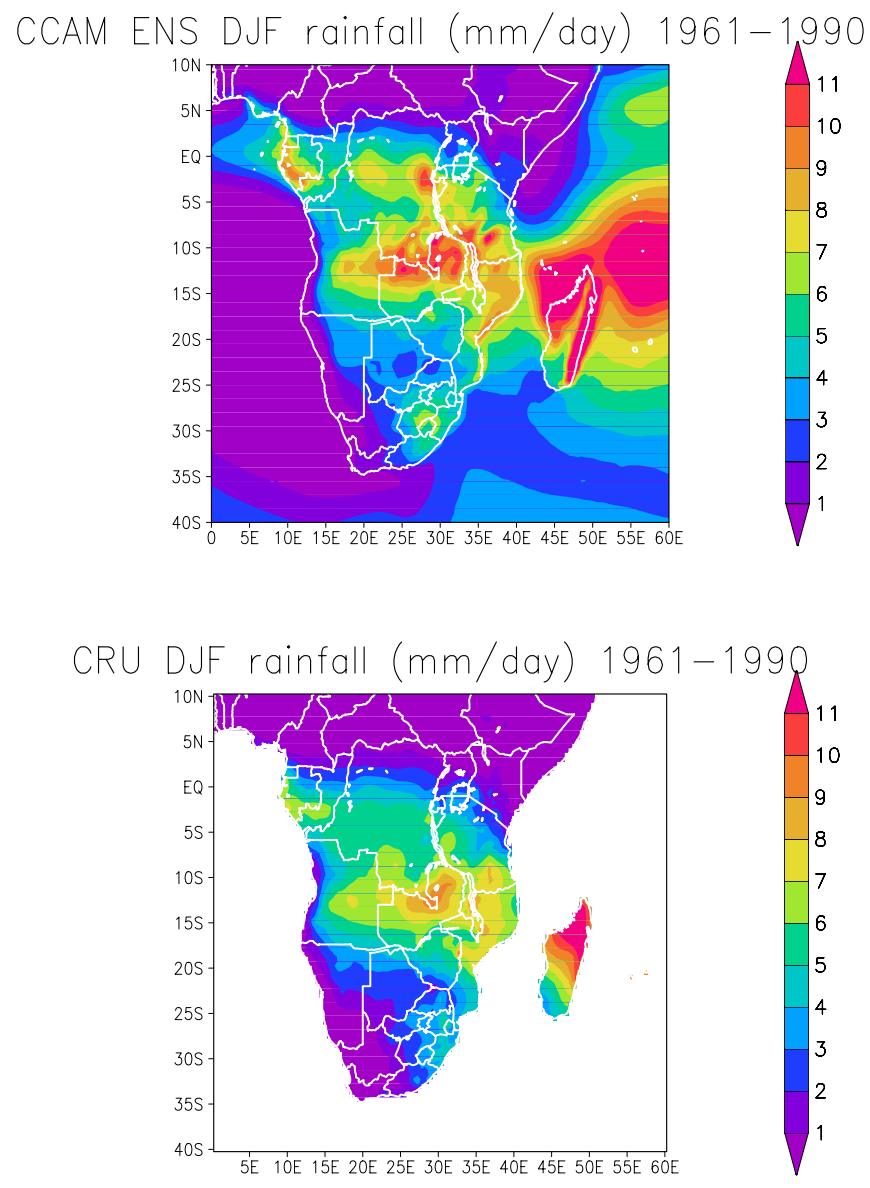

Figure 3

Ensemble average of the 6 regional CCAM simulations for summer (DJF) rainfall over Southern Africa and tropical Africa - for the period 1961-1990 (top panel). The corresponding CRU (observed) fields are shown in the lower panel. Units are $\mathrm{mm} / \mathrm{d}$.

bias is as large as $2 \mathrm{~mm} / \mathrm{d}$. An in-depth verification of the simulations of present-day climate falls beyond the scope of this paper. More details of CCAM's ability to simulate not only the mean climatology but also the intra-annual cycle of rainfall, the intra-annual cycle in circulation and daily circulation statistics over Southern Africa are provided by Engelbrecht (2005), Engelbrecht et al. (2009) and Potgieter (2009).

The projected changes in summer rainfall over Southern Africa (expressed as a percentage change) are shown in Fig. 4, for the period 2071-2100 relative to 1961-1990 under the A2 SRES scenario. The $25^{\text {th }}$ percentile, median and $75^{\text {th }}$ percentile of the ensemble of projected changes are shown. The 6 downscalings convey a robust message of change East Africa is projected to become generally wetter, whilst Southern Africa is projected to become generally drier (with a relatively strong signal of drying projected for Zimbabwe, Zambia and Angola). The central interior of South Africa is projected to become somewhat wetter, despite the general drying signal projected for Southern Africa. At the subcontinental scale, the CCAM projected signals are consistent with those of the majority of CGCM projections described in AR4 of the IPCC. Although an in-depth discussion of the CCAM projected rainfall signal falls beyond the scope of this paper, aspects of the underlying circulation dynamics are described by Engelbrecht et al. (2009) and Potgieter (2009).
DJF 75perc change 2071-2100 vs 1961-1990
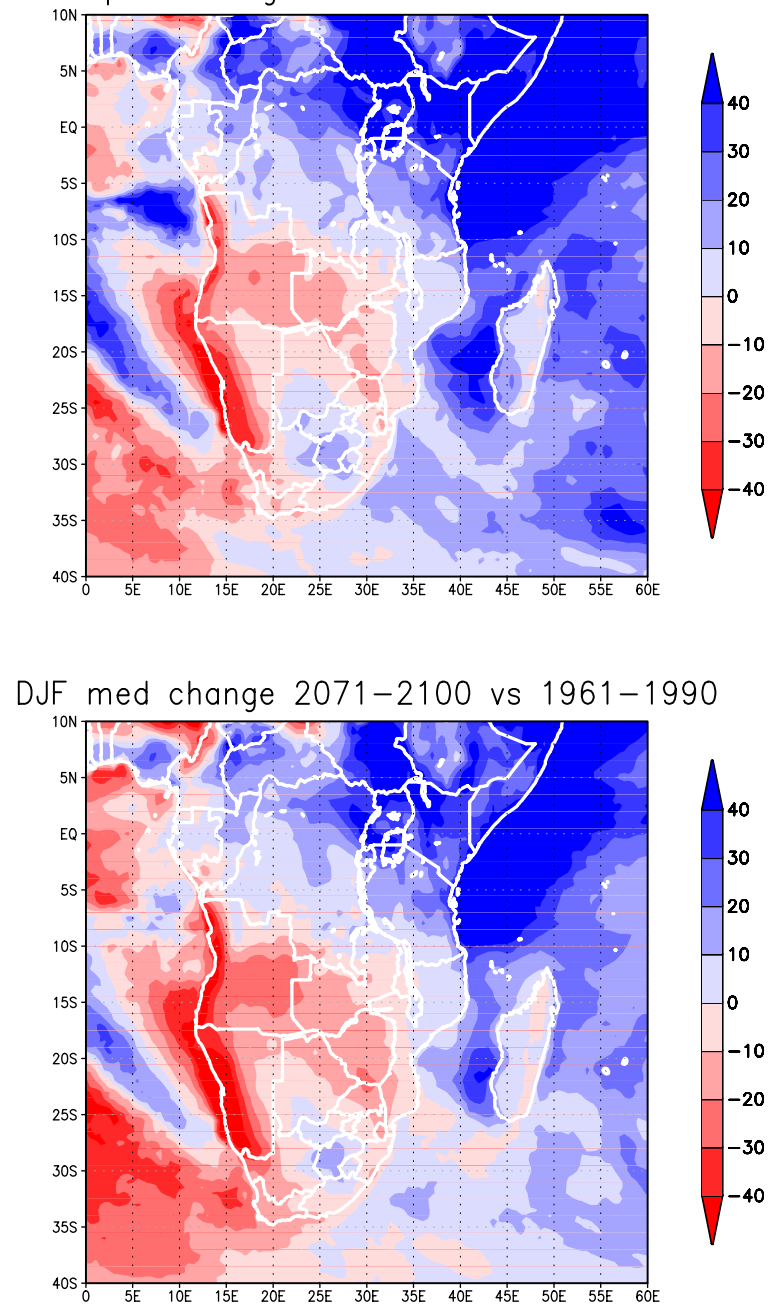

DJF 25perc change $2071-2100$ vs $1961-1990$

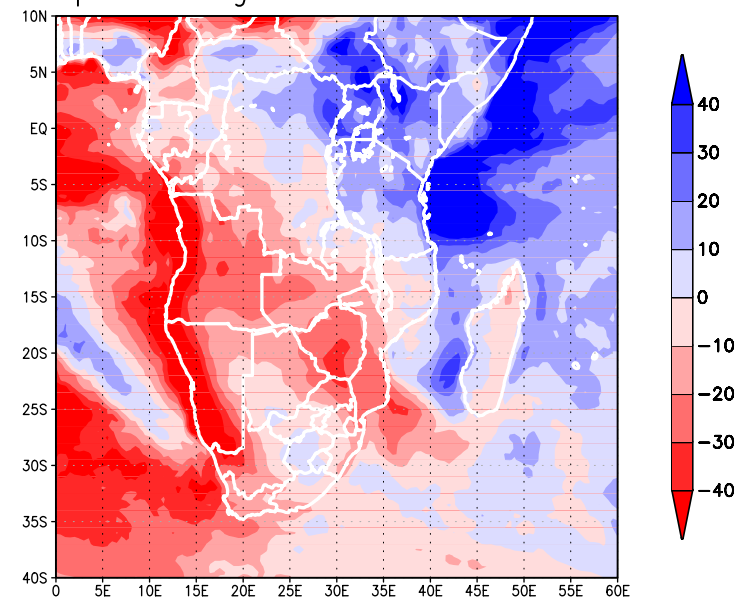

Figure 4

Projected change in summer (DJF) rainfall (expressed as a percentage change) over Southern and tropical Africa from the CCAM downscalings of 6 CGCMs, for the period 2071-2100 relative to 1961-1990 under the A2 SRES scenario. The upper panel shows the $75^{\text {th }}$ percentile of the ensemble of projections of change in summer rainfall, the middle panel shows the median, and the bottom panel shows the $25^{\text {th }}$ percentile. 


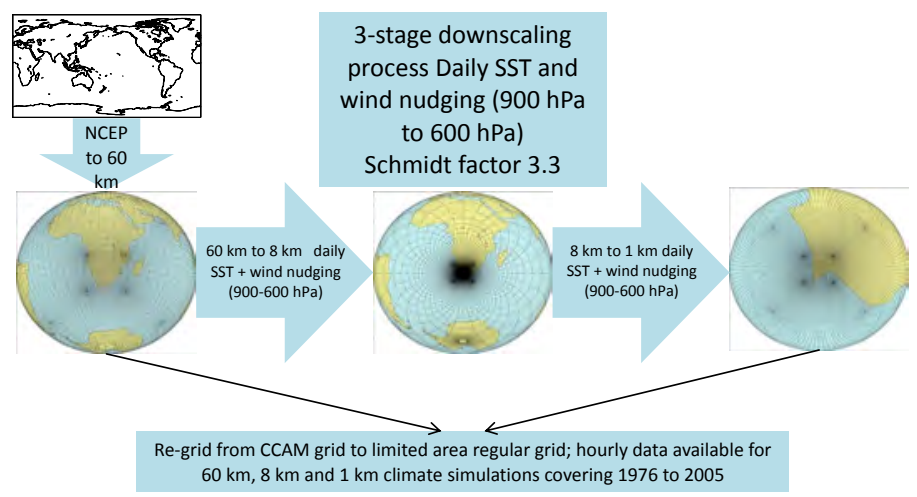

Figure 5

Schematic of the dynamical downscaling procedure used to obtain the ultra-high resolution simulations over the False Bay area in the south-western Cape of South Africa. Downscaling was performed from the low-resolution NCEP data to a resolution of about $60 \mathrm{~km}$ over Southern Africa and from there to $8 \mathrm{~km}$ resolution over the south-western Cape and finally $1 \mathrm{~km}$ resolution over the False Bay area.

\section{Climate simulations at ultra-high resolution}

This section reports on an experiment which illustrates that CCAM can be applied across multiple spatial scales, ranging from relatively low-resolution global simulations, to resolutions as high as $1 \mathrm{~km}$ over selected areas of interest.

A multiple-nudging strategy was followed in order to obtain $8 \mathrm{~km}$ and $1 \mathrm{~km}$ resolution simulations of present-day climate over the south-western Cape in South Africa. The first phase in the downscaling (Fig. 5) involved integrating CCAM in stretched-grid mode over Southern Africa, at a resolution of about $60 \mathrm{~km}$. The grid was quite strongly stretched (Schmidt factor 3.3), so that the model resolution decreased to about $700 \mathrm{~km}$ in the far-field. Away from the high-resolution region over Southern Africa, CCAM was provided with synoptic-scale forcing of atmospheric circulation, from the $2.5^{\circ}$ (about $250 \mathrm{~km}$ ) resolution National Centers for Environmental Prediction (NCEP) reanalysis data set (Kalnay et al., 1996). This forcing was provided at 6-hourly intervals for the period 1976-2005. SSTs from the NCEP data set were used as lower boundary forcing. An $8 \mathrm{~km}$ resolution simulation (Schmidt stretching factor 24.75) over the south-western Cape was subsequently performed for the same period, by far-field nudging of CCAM within the 6 -hourly output of the $60 \mathrm{~km}$ resolution simulation. Finally, the $8 \mathrm{~km}$ resolution simulations were downscaled to $1 \mathrm{~km}$ resolution (Schmidt factor 200), over an area of about $50 \mathrm{~km}$ x $50 \mathrm{~km}$ over and around False Bay. For all 3 phases of the downscaling performed, grid-point nudging of the wind field was applied from about $900 \mathrm{hPa}$ and higher, outside the area of high resolution. More detail on the experimental design of these simulations is provided by Roux (2009). These simulations nudged within the NCEP reanalysis data, may be regarded as a way to obtain a high-resolution regional reanalysis, although regional observations are not assimilated into the simulations. Similar experiments were recently performed over Tasmania using CCAM (Corney et al., 2010). All the simulations described here were performed on the C4 cluster of the Meraka Institute of the CSIR in South Africa, and illustrate the flexibility of the CCAM downscaling procedure to provide ultra-high resolution simulations for extended integration periods.
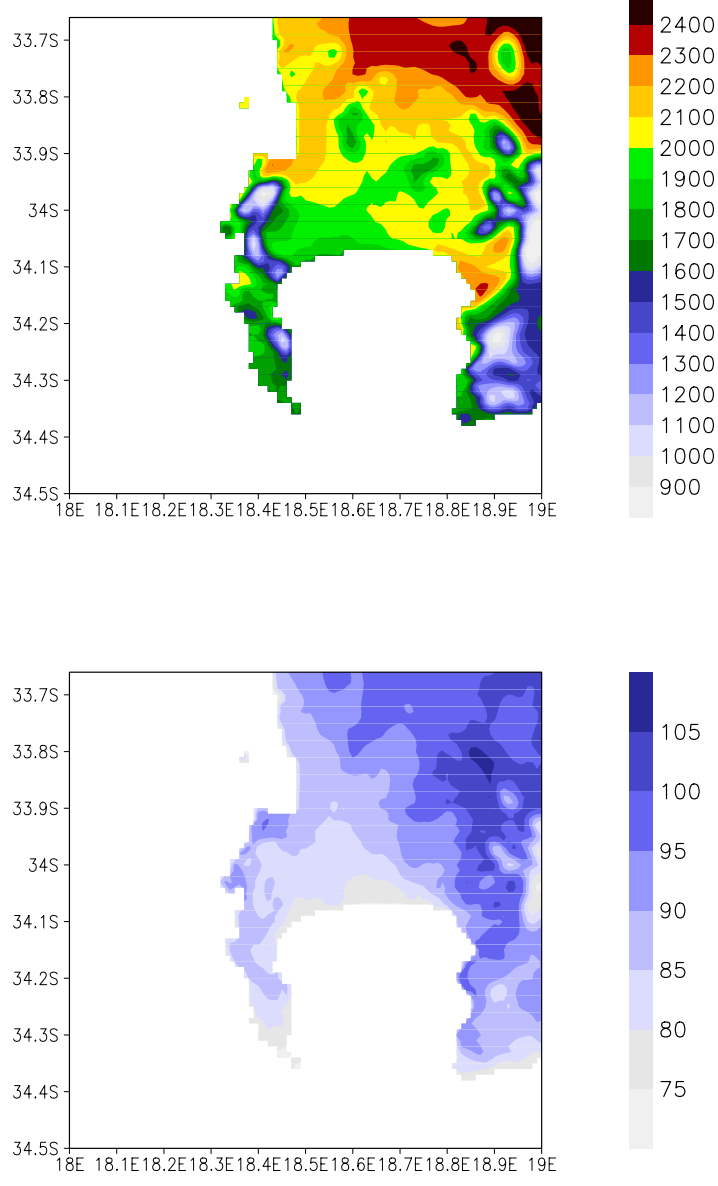

Figure 6

A detailed (1 $\mathrm{km}$ resolution) simulation of the spatial variation of GDD over a wine-producing region in the south-western Cape of South Africa (top panel). The simulated spatial variation in the inter-annual variability of the GDD is quantified by the relevant standard deviation map (bottom panel).

A motivation for performing these ultra-high resolution simulations over the south-western Cape of South Africa is to provide a detailed description of the potential for wine-grape production. The concept of growing degree days (GDD) is used widely as a climate index that characterises the suitability of a location for viticulture, and is a measure of heat accumulation over the growing season (September to March) (see Jones et al., 2010). The quality of wine grapes is highly sensitive to temperature, in particular temperature extremes, and these aspects are taken into account in the calculation of the GDD. The 1 $\mathrm{km}$ simulations provide a detailed simulated distribution of the GDD over the area of interest (Fig. 6 top) - at a spatial resolution higher than that available from the network of weather stations over the region. The interior regions situated in the north-eastern part of the domain are simulated to have the largest GDD. The moderating effect of the ocean on the GDD can be seen in most of the coastal regions and in particular over the western parts of the False Bay region. This region is known to be subjected to the frequent occurrence of sea breezes (e.g. Bonnardot et al., 2005). The potential value of the ultra highresolution simulations to viticulturists is demonstrated by the simulation of localised features such as the relatively larger GDD along Table Bay and the eastern shore of False Bay. In both these areas, the relatively larger GDD occur alongside regions of steep topography. The steep topography acts to 


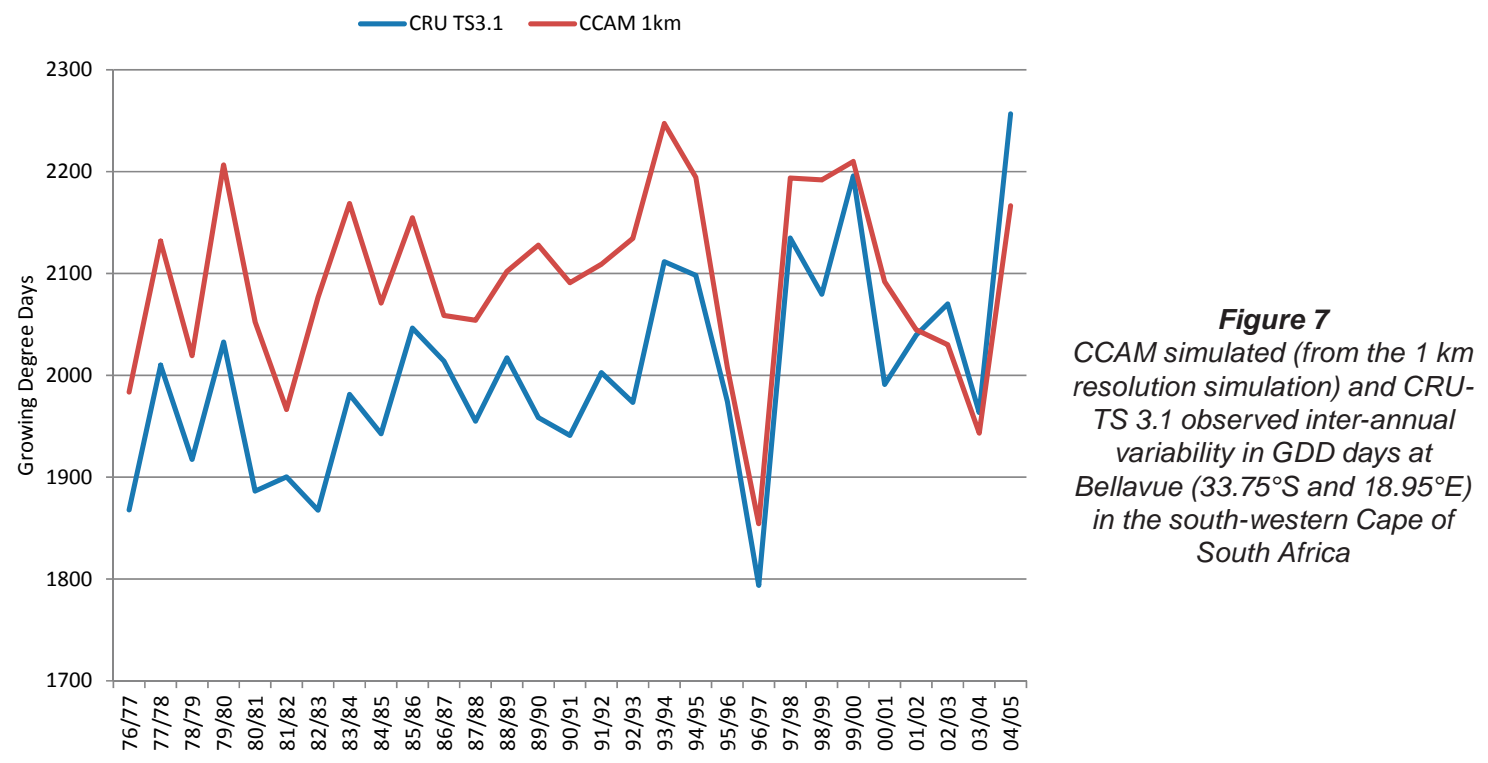

shield these localised areas from exposure to the sea breeze, and enhances warming over these areas during the occurrence of down-slope winds. The simulated spatial variation in the interannual variability of GDD is quantified by the relevant standard deviation map (Fig. 6 bottom). The coastal regions and the regions of high topography exhibit the least interannual variability, while the interior, in particular valleys, exhibit the largest interannual variability. These detailed simulations of the GDD, in combination with other variables, may be used to provide guidance on the most suitable locations for growing specific varieties of grapes over the region (provided of course, that the simulations are of sufficient accuracy).

Verification of the $1 \mathrm{~km}$ simulations is problematic, due to the comparatively low spatial density of the observational network and the lack of stations with sufficiently long time series of data. Roux (2009) reports in more detail on the validation of these simulations, including verification of the model simulations of intra-annual variability over the region against weather station data. Here the simulations are verified by comparison of the simulated interannual variability of the GDD at Bellavue $\left(33.75^{\circ} \mathrm{S}\right.$ and $\left.18.95^{\circ} \mathrm{E}\right)$, over the period $1976-2005$, to the observed variability of the CRU-TS 3.1 data (Mitchell and Jones, 2005) over the same area (Fig. 7). The observed interannual variability is captured remarkably well in the CCAM simulation, suggesting that the downscaling procedure was successful in translating the lower-boundary and synoptic-scale forcing to the micro-scale. Of particular interest is the 1996/1997 season, which was observed to be the growing season with the smallest accumulation of GDD over the 30-year period. The occurrence of this anomalous season is captured in CCAM, further illustrating that the downscaling procedure may be utilised for interannual climate variability studies at ultra-high resolution. It may be noted that for the case of the monthly CRU-TS 3.1 data, the GDD was determined without accounting for days where the maximum temperature exceeded $35^{\circ} \mathrm{C}$ or where the minimum temperature was below $10^{\circ} \mathrm{C}$ (due to the monthly time-resolution of the data, see Jones et al., 2010).

\section{Seasonal forecasting}

Objective forecast system development for Southern African seasonal rainfall and temperature anomalies has been ongoing since the early 1990s (e.g. Jury, 1996; Mason, 1998; Jury et al.,
1999; Landman and Mason 1999), because it has been found that the seasonal-to-interannual variability of these anomalies over Southern Africa are predictable (e.g. Klopper et al., 1998; Landman and Goddard, 2002; Reason and Rouault, 2005; Tennant and Hewitson, 2002). In the late 1990s, a small number of institutions in South Africa started to invest in the implementation and running of atmospheric global climate models (AGCMs) for the purpose of seasonal forecast production based on physical models. One such model is CCAM. This AGCM has been used for routine seasonal forecasting since 2007 at the University of Pretoria (e.g. Le Roux, 2009) and since 2010 at the Council for Scientific and Industrial Research (CSIR) (Landman et al., 2010b). The model was one of the AGCMs contributing to South Africa's first ever multi-model seasonal rainfall forecast system developed at the South African Weather Service (SAWS; Landman et al., 2009). During this time, Atmospheric Model Inter-Comparison Project (AMIP) simulations (Gates, 1992) were performed by forcing the model with observed SSTs over a 25-year period from 1979 to 2005, producing an ensemble of 6 members (e.g. Le Roux, 2009). The model was initialised using a lagged-average forecasting approach. CCAM was applied at quasi-uniform resolution of about $200 \mathrm{~km}$ (Fig. 1) on the same conformal-cubic grid used for the global climate simulations described earlier.

At present CCAM is in the process of being configured as a so-called multi-scale or seamless operational forecasting system (Landman et al., 2010b) at the CSIR. This system will supplement the multi-model seasonal forecasting effort in South Africa (Landman and Beraki, 2010) under the auspices of the SAWS. As stated above, CCAM is also being used for climate-change projections, and so the use of this model on multi-decadal time scales and for operational seasonal-tointerannual variation predictions will subsequently strengthen the link between the seasonal forecast and multi-decadal climate change modelling communities in southern Africa (e.g. Doblas-Reyes et al., 2006).

The ability of the CCAM simulation set to describe the observed seasonal-to-interannual rainfall variability over Southern Africa during the peak of the austral summer period, i.e. December to February (DJF), is assessed here. Verification is performed for the 24 DJF seasons, from $1979 / 80$ to $2002 / 03$.

The approximately $200 \mathrm{~km}$ horizontal resolution of 
CCAM used here is too coarse to represent local sub-grid features, possibly contributing to the raw model simulations overestimating seasonal rainfall totals, as has been found for other models applied at similar resolutions (e.g. Mason and Joubert, 1997). However, it has been demonstrated that such biases over southern Africa can be minimized through statistical post-processing of the model data (e.g. Landman and Goddard, 2002). Model output statistics (MOS) equations are developed here because they can compensate for systematic deficiencies in the AGCM directly in the regression equations (Wilks, 2006). Since it has been found that the $850 \mathrm{hPa}$ geopotential height field is a good predictor in a MOS system, this CCAM output variable is used to produce rainfall simulations at approximately $50 \mathrm{~km}$ horizontal resolution. In fact, for the portion of the Southern African region considered (south of $15^{\circ} \mathrm{S}$ ), using CCAM's seasonal rainfall output instead of its $850 \mathrm{hPa}$ geopotential height fields in the MOS equations, produces inferior results especially over the western parts of the region (not shown). The MOS equations are developed by using the canonical correlation analysis (CCA) option of the Climate Predictability Tool (CPT) of the IRI (http://iri.columbia.edu). CCAM's 850 hPa geopotential field used in the MOS is restricted to a domain that covers an area between the equator and $45^{\circ} \mathrm{S}$, and $15^{\circ} \mathrm{W}$ to $60^{\circ} \mathrm{E}$. Empirical orthogonal function (EOF) analysis is performed on both the predictor (CCAM's $850 \mathrm{hPa}$ geopotential height fields) and predictand sets (CRU-TS $3.10 .5^{\circ} \mathrm{x} 0.5^{\circ}$ resolution DJF seasonal rainfall totals - the option of the CPT is used that transforms the rainfall data into an approximate normal distribution) prior to CCA, and the number of EOF and CCA modes to be retained in the CPT's CCA procedure is determined using cross-validation skill sensitivity tests. The EOF analysis is performed on correlation matrices of the predictor and predictand sets.

In order to minimise the chance of obtaining biased results, cross-validation is performed on the ensemble mean, therefore estimating CCAM's ability to produce interannual deterministic output for mid-summer rainfall over Southern Africa. A large 5-year-out window is used, meaning that 2 years are omitted on either side of the predicted year. The verification measures presented for testing the simulation output of CCAM are the Kendall rank correlation coefficient commonly referred to as the Kendall's tau, and the mean squared error skill score (MSESS; Wilks, 2006). For the latter verification measure, climatology is used as the reference forecast. Kendall's tau is considered a robust (to deviation from linearity) and resistant (to outlying data) alternative to Pearson or 'ordinary' correlation, and also measures discrimination (are the forecasts discernibly different given different outcomes?).

A spatial description of CCAM's skill in simulating summer rainfall over Southern Africa, over the 24-year test period provided by the AMIP simulations, is provided by Kendall's tau correlations between observed and simulated DJF rainfall (Fig. 8). For local significance, Kendall's tau values larger than 0.34 are significant at the $99 \%$ level, values larger than 0.25 are significant at $95 \%$, and values larger than 0.19 are significant at the $90 \%$ level. The area of largest correlation is found over the north-eastern parts of the study area and includes the larger part of Zimbabwe and central Mozambique, Botswana and parts of South Africa, including the far north-eastern South African area adjacent to Zimbabwe. This latter high-skill area over South Africa has also been identified by other physical models which have
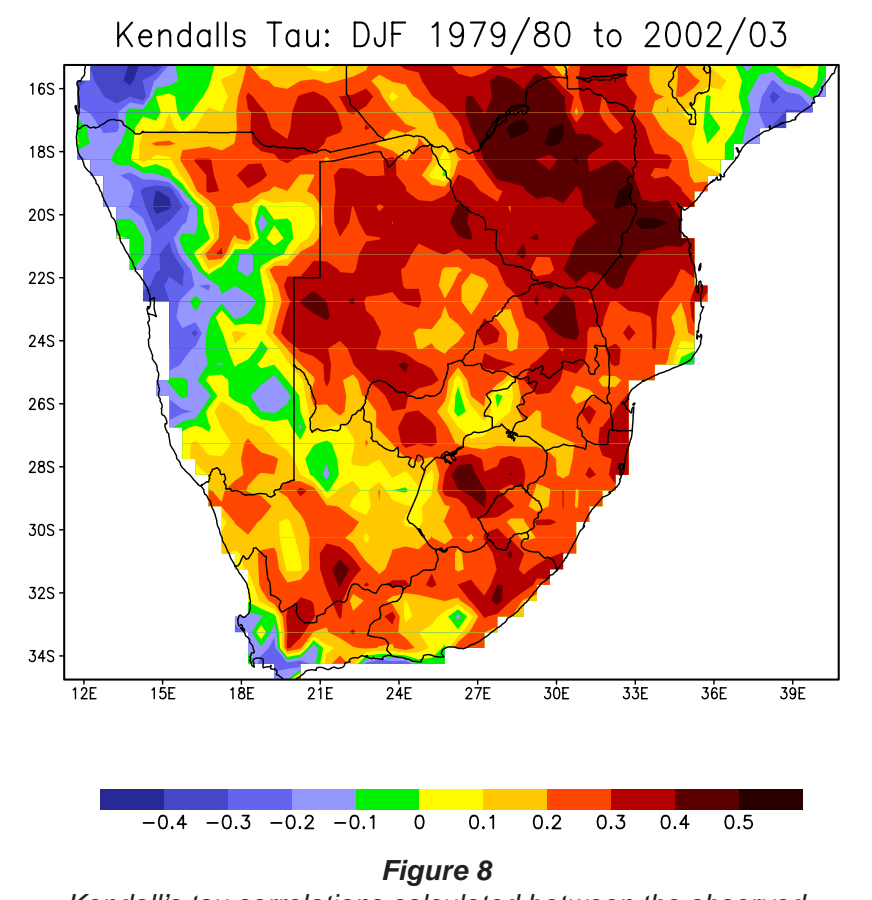

Kendall's tau correlations calculated between the observed and downscaled CCAM DJF rainfall simulations over the 27-year test period from 1979/80 to 2002/03

been verified in a true operational forecast setting (Landman et al., 2011) as an area of high mid-summer rainfall forecast skill, supporting the results that are being presented here for CCAM.

A temporal description of CCAM's skill in simulating the interannual variations in mid-summer rainfall over Southern Africa is provided next. Figure 9 shows simulated vs. observed rainfall indices for a number of regions, which are defined as follows: 'Zimbabwe' covers the region $15.25^{\circ} \mathrm{S}$ to $22.75^{\circ} \mathrm{S}$ and $24.75^{\circ} \mathrm{E}$ to $32.75^{\circ} \mathrm{E}$; 'Botswana' covers $16.75^{\circ} \mathrm{S}$ to $25.75^{\circ} \mathrm{S}$ and $19.75^{\circ} \mathrm{E}$ to $28.75^{\circ} \mathrm{E}$; 'Eastern South Africa' stretches from $22.75 \mathrm{~S}^{\circ}$ to $33.75 \mathrm{~S}^{\circ}$ and $24.75^{\circ} \mathrm{E}$ to $32.75^{\circ} \mathrm{E}$; and 'Western South Africa' ranges from $25.75^{\circ} \mathrm{S}$ to $33.75^{\circ} \mathrm{S}$ and $19.75^{\circ} \mathrm{E}$ to $24.75^{\circ} \mathrm{E}$. For each of these regions, the simulated and observed rainfall over the specified gridded areas is areaaveraged and then normalised in order to produce a set of rainfall indices. All the Kendall's tau values are significant at least at the $95 \%$ level of confidence $(\mathrm{p}<0.05)$, and the MSESS values for all regions, excluding 'Western South Africa' which receives most of its annual rainfall during autumn, indicating that CCAM outscores the use of the observed climatology as an indication of the rainfall for each year. The best result is obtained for 'Zimbabwe' where the model simulations explain $45 \%$ of the rainfall variance $\left(R^{2}=0.45\right)$.

\section{Short-range forecasting}

The application of a climate model for operational short-range weather forecasting effectively implies that the model is subjected to a daily test - for example, the model's ability to simulate convective rainfall can be verified against observations. This section reports on a large set of hindcasts designed to verify CCAM's skill in short-range weather forecasting over Southern Africa. The model was integrated using the same stretched grid applied to perform the regional projections of climate change (Fig. 2). Hindcasts were performed for the 
Figure 9

Area-averaged observed DJF rainfall indices (blue) over 4 Southern African regions as specified in the text, vs. the corresponding downscaled CCAM hindcast indices (green). The years on the $x$-axes refer to the December months of the DJF seasons. Kendall's tau correlations and associated $p$-values, and mean squared error skill scores with climatology as a reference forecast (MSESS) are shown.
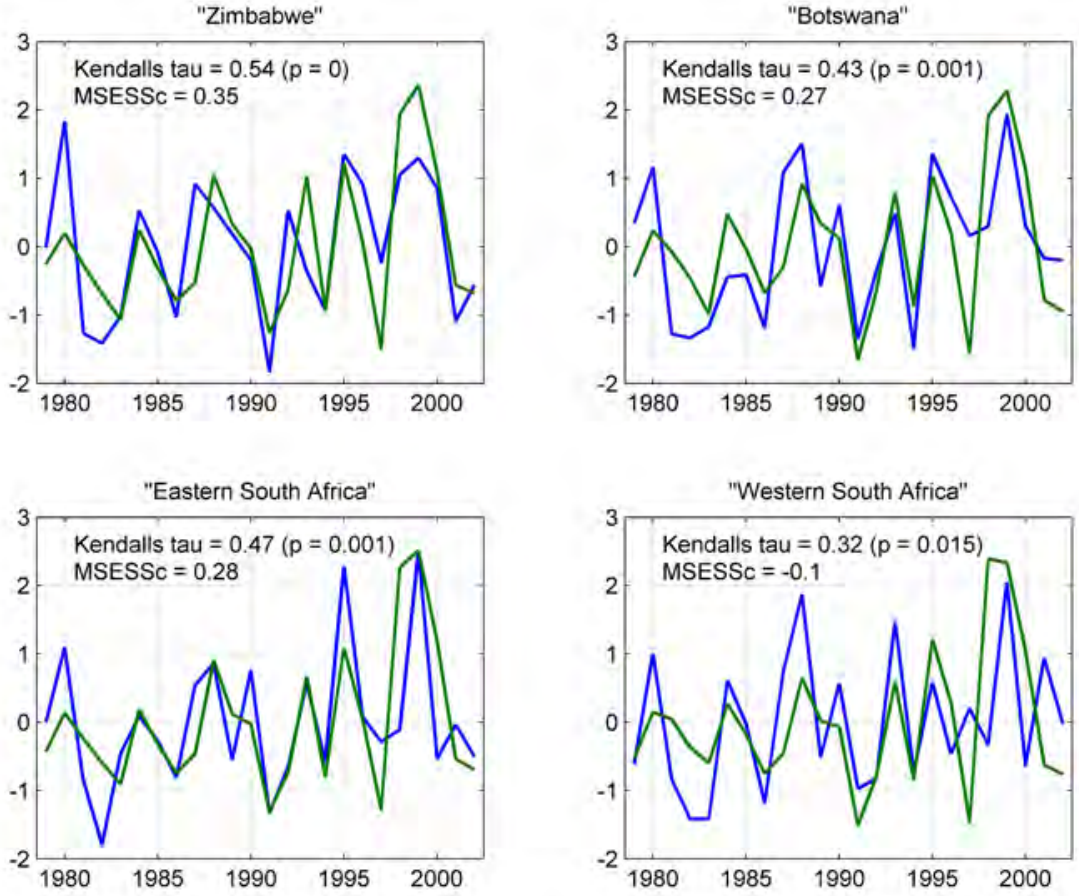

summer seasons (December to February) of 2006/7, 2007/8 and 2008/9, using initial conditions provided by the Global Forecasting System (GFS). The model ran in stand-alone mode (that is, it was not nudged within the output of a global forecast, unlike in the case of NWP using typical limited-area models). After initialisation, the model was integrated $7 \mathrm{~d}$ into the future, thereby enabling studies that investigate the skill of the forecasts as a function of model integration time. For example, Potgieter (2006) has shown that CCAM provides skilful forecasts of circulation patterns over Southern Africa for integration periods of at least $4 \mathrm{~d}$ into the future. All the simulations described here were performed on the Sun Hybrid System of the CHPC in South Africa.

Verification of the CCAM forecasts are based on daily rainfall data for the periods under consideration, as recorded by weather stations of SAWS and the Agricultural Research Council (ARC). Gridded daily rainfall data were constructed from the weather stations at a resolution of 0.25 degrees (Landman et al., 2010a). The forecasts were interpolated to the same grid in order to facilitate the model verification. The bias of the forecasts in representing daily summer (December to February, DJF) rainfall totals over South Africa (for the first day of model integration) is displayed in Fig. 10. The model has a general wet bias in predicting summer rainfall $(0.58 \mathrm{~mm} / \mathrm{d}$ on average and as large as $2 \mathrm{~mm} / \mathrm{d}$ over parts of the eastern Free State). The Brier skill score (BSS) of the forecasts in predicting $24 \mathrm{~h}$ summer rainfall totals (first day of model integration) is displayed in Fig. 11 for various rainfall thresholds. Persistence was used as the reference forecast in calculation of the BSS. The forecasts are in general not skilful in predicting the occurrence or non-occurrence of rainfall above the threshold of $1 \mathrm{~mm}$ - as a result of the model predicting a frequency of such events which is too high (see Landman et al., 2010a). The forecast of rainfall events above the $10 \mathrm{~mm} / \mathrm{d}$ threshold is skilful over most of the country, the exceptions being regions along the eastern escarpment and the lowveld of eastern South Africa. The threshold of more than $25 \mathrm{~mm}$ of rain occurring over a $0.5^{\circ} \times 0.5^{\circ}$ area within a

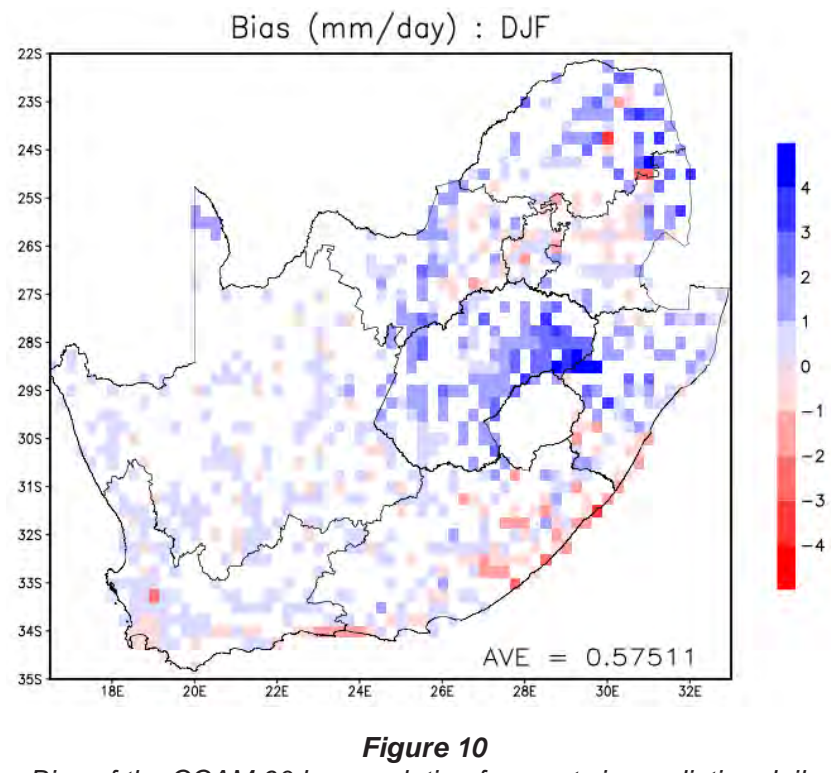

Bias of the CCAM $60 \mathrm{~km}$ resolution forecasts in predicting daily rainfall totals over Southern Africa (for the first day of model integration)

24-hour period represents the $95^{\text {th }}$ percentile of rainfall occurrences over the summer rainfall region of South Africa (e.g. Dyson, 2009). The model forecasts of rainfall exceeding this threshold have skill over persistence for most of the country.

It is likely that the inherent model errors responsible for the wet bias in predicting summer rainfall over South Africa, and the lack of skill in predicting the occurrence or non-occurrence of rainfall events for small thresholds, will also affect simulations performed at climate-change time scales. Similarly, if the model forecasts at the short-range time scales can be improved, for example by improving the cumulus parameterisation scheme applied within the model, the improvements are likely to carry over to the climate simulations. The improvement of the cumulus convection 

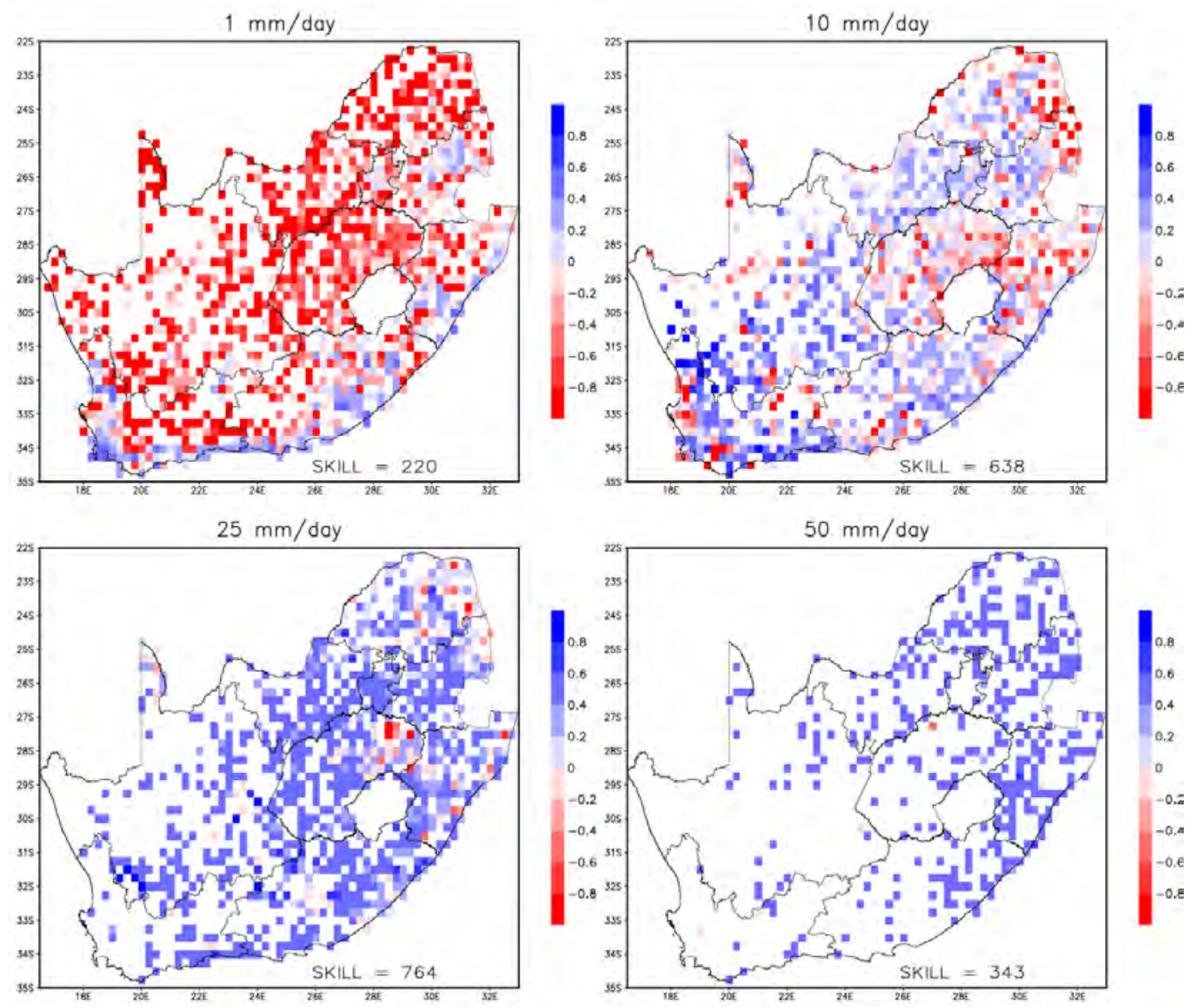

Figure 11

Brier skill score (BSS) of the CCAM forecasts of daily rainfall totals (for the first day of model integration), using persistence as the reference forecast schemes applied within climate models, through gaining new insights into the thermodynamics and dynamics of convection over Southern Africa, is an area of research that is starting to receive more attention in South Africa (e.g. Engelbrecht et al., 2007; Bopape and Engelbrecht, 2011).

The hindcasts described here were designed to closely match the experimental design of the regional climate simulations described earlier. Hindcasts have additionally been performed at a much higher spatial resolution $(15 \mathrm{~km}$ in the horizontal) over the Southern African region. More in-depth descriptions of the forecast accuracy and skill, for both the 60 $\mathrm{km}$ and $15 \mathrm{~km}$ resolution forecasts, are provided by Landman et al. (2010a) and Ghile and Schulze (2008). In these studies, it is shown that the short-range forecasts of CCAM and the Unified Model (used for operational weather forecasting at SAWS) have similar skill over the Southern African region, and that there is potential for the development of a multi-model short-range weather-forecasting system in South Africa. It may also be noted that an operational weatherforecasting system, that involves the application of CCAM at resolutions of $60 \mathrm{~km}$ and $15 \mathrm{~km}$, has been configured at the CSIR in South Africa (Landman et al., 2010a).

\section{Conclusions}

This paper provides evidence of the successful application of a single atmospheric model code at time scales ranging from short-range weather forecasting through to projections of future climate change, and at spatial scales that vary from relatively low-resolution global simulations, to ultra-high resolution simulations at the micro-scale. The model used for these experiments is the variable-resolution global atmospheric model, CCAM. Originally developed for the purpose of regional climate modelling, CCAM has been shown to satisfactorily simulate many key attributes of the present-day climate over Southern Africa, including the intra-annual cycle in rainfall and circulation (Engelbrecht et al., 2009) and the daily statistics of closed-low frequencies and extreme rainfall events (Potgieter, 2009). Recently, CCAM has been used to obtain a large ensemble of detailed projections of future climate change over Southern Africa under the A2 emission scenario. The sea-ice and bias-corrected SSTs (see Katzfey et al., 2009) of 6 CGCM projections from AR4 of the IPCC were used as lower-boundary forcing in CCAM simulations performed for the period 1961-2100, at a quasi-uniform resolution of about $200 \mathrm{~km}$. These were subsequently downscaled to a resolution of about $60 \mathrm{~km}$ over Southern Africa, using a spectral nudging technique (Thatcher and McGregor, 2010a; 2010b). Summers over the Southern African region are projected to become generally drier in response to enhanced anthropogenic forcing (an exception being the central interior of South Africa), with east Africa projected to become generally wetter. The strongest signal of drying is projected over Zimbabwe and Botswana.

Its variable-resolution formulation and multiple-nudging capabilities make CCAM a flexible tool for the dynamic downscaling of CGCM simulations or reanalysis data to very high spatial resolutions. By applying a multiple-nudging approach, NCEP reanalysis data have been downscaled to a resolution of about $60 \mathrm{~km}$ over Southern Africa and tropical Africa, and subsequently to $8 \mathrm{~km}$ resolution over the southwestern Cape and $1 \mathrm{~km}$ resolution over a small region around 
False Bay in South Africa. Some detailed verification of these ultra-high resolution simulations against observations is provided by Roux (2009). The simulations have the potential to provide guidance on the spatial distribution of variables such as growing degree days at the scale of vineyards. The $1 \mathrm{~km}$ resolution simulations have been shown to capture the interannual variation of growing-degree days at the scale of individual weather stations. This implies that the lowerboundary forcing and synoptic-scale forcing provided by the NCEP reanalysis data have been successfully downscaled to the $1 \mathrm{~km}$ resolution grid, to reflect interannual variation in climate at the point scale. This flexibility of CCAM to function as a downscaling tool across multiple time scales has also been demonstrated in high-resolution simulations over Fiji (Lal et al., 2008) and very high resolution simulations over Tasmania (Corney et al., 2010).

The AMIP simulations presented here illustrate that quasi-uniform CCAM simulations of seasonal circulation are capable of skilfully representing observed interannual variability of mid-summer rainfall over the region. This illustrates the potential of the model for operational seasonal forecasting over Southern Africa, provided that realistic SST forcing is available as lower boundary forcing (Landman et al., 2011). Indeed, CCAM is being used to produce operational seasonal forecasts over the Southern African region (Landman et al., 2010b), and these model forecasts also feed into a multi-model seasonal forecasting system hosted by the SAWS. With ENSO being a dominant factor in determining interannual variability in rainfall over Southern Africa, the skilful representation of this variability in the AMIP simulations is an indication that the model also realistically simulates the response of atmospheric circulation over Southern Africa to ENSO-related lower-boundary forcing. The realistic representation of observed interannual variability provides an important test for CGCMs and RCMs that are used for the projection of future climate change, indicating whether the models are capable of simulating the atmospheric response to some of the fundamental forcings of present-day climate (for example, the impact of ENSO on Southern African rainfall variability). Incidentally, the simulations of interannual variability presented here are particularly skilful over Zimbabwe and Zambia - regions where the model projections of future drying of the Southern African region show a particularly strong signal. At the short-range time scale, CCAM has been shown to provide skilful forecasts of daily circulation patterns (Potgieter, 2006) and of daily rainfall totals (see also Landman et al. (2010a)). In fact, CCAM is also applied for operational short-range weather forecasting in South Africa (Landman et al., 2010b). Operational weather forecasting and related hindcasts provide the opportunity to regularly test the performance of models that are traditionally run at climatechange time scales. It is noted that over the Southern African region, testing the model's performance in simulating the occurrence of convective rainfall is of particular importance.

The research presented in this paper illustrates the flexibility of variable-resolution global climate models, and in particular CCAM, to provide atmospheric simulations across a range of scales, both spatially and temporally. Future work at the CSIR is to focus on the coupling of CCAM to a cubebased ocean model, in collaboration with CSIRO and the Japanese Agency for Marine-Earth Science and Technology (JAMSTEC). This capability will provide opportunities to further improve the capacity for multi-scale simulations, including the palaeo-time scales. The existing short-range and seasonal forecasting systems and regional climate-change projection system based on CCAM are also to be optimised through continued model verification and improvement activities, with specific focus on convective processes.

\section{Acknowledgements}

We would like to express our gratitude to the Centre for High Performance Computing (CHPC) of the Meraka Institute of the CSIR, for excellent support whilst performing the large set of climate- change projections described in the paper. The ultra-high resolution simulations were performed on the C4 cluster of the Meraka Institute - we are indebted to Albert Gazendam for his support of these experiments. The WRC has funded, and currently still funds, a number of projects in which CCAM is applied over Southern Africa. A CSIR Parliamentary Grant, as well as the European Commission by means of the FP7 collaborative project "Climate Change and Urban Vulnerability in Africa (CLUVA)”, contract no. 265137, have provided funding to CSIR to perform the new set of projections of future climate change over Africa. The Wine Industry Network of Expertise and Technology (Winetech) has provided funding to the ARC for the ultra-high resolution simulations described in the paper. Finally, the research on climate variability and seasonal forecasting described in the paper is supported by the SATREPS (Science and Technology Research Partnership for Sustainable Development) program of the Japanese government, through a collaborative research project between the Applied Centre for Climate and Earth System Studies (ACCESS) in South Africa, JAMSTEC and the University of Tokyo.

\section{References}

BOPAPE MJ and ENGELBRECHT FA (2011) Introducing a moisture scheme to a nonhydrostatic sigma coordinate model. Proc. $27^{\text {th }}$ Annual Conference of the South African Society for Atmospheric Sciences, September 2011, Hartebeeshoek, South Africa.

BONNARDOT V, PLANCHON O and CAUTENET S (2005) Sea breeze development under an offshore synoptic wind in the South-Western Cape and implications for the Stellenbosch wineproducing area. Theor. Appl. Climatol. 81 203-218. DOI: 10.1007/ s00704-004-0087-y.

CHOUINARD C, BÉLAND M and McFARLANE N (1986) A simple gravity wave drag parameterization for use in medium-range weather forecast models. Atmos. Ocean 24 91-110.

CORNEY SP, KATZFEY JJ, McGREGOR JL, GROSE MR, BENNETT JC, WHITE CJ, HOLZ GK, GAYNOR SM and BINDHOFF NL (2010) Climate Futures for Tasmania: Climate Modeling. Antarctic Climate and Ecosystems Technical Report. 81 pp. ISBN: 978-1-921197-06-2.

DAVIES T, CULLEN MJP, MALCOLM AJ, MAWSON MH, STANIFORTH A, WHITE AA and WOOD N (2005) A new dynamical core for the Met Office's global and regional modelling of the atmosphere. Quart. J. R. Meteorol. Soc. 131 1759-1782.

DOBLAS-REYES FJ, HAGEDORN R, PALMER TN and MORCRETTE J-J (2006) Impact of increasing greenhouse gas concentrations in seasonal ensemble forecasts. Geophys. Res. Lett. 33 L07708. DOI:10.1029/2005GL025061.

DYSON LL (2009) Heavy daily-rainfall characteristics over the Gauteng Province. Water SA 35 627-638.

ENGELBRECHT FA, RAUTENBACH CJ DEW, McGREGOR JL and KATZFEY JJ (2002) January and July climate simulations over the SADC region using the limited-area model DARLAM. Water SA 28 361-374.

ENGELBRECHT F (2005) Simulations of climate and climate change over southern and tropical Africa with the conformalcubic atmospheric model (Chapter 4). In: Schulze RE (ed.) 
Climate Change and Water Resources in Southern Africa: Studies on Scenarios, Impacts, Vulnerabilities and Adaptation. WRC Report No. 1430/1/05. Water Research Commission, Pretoria, South Africa. pp. 57-74.

ENGELBRECHT FA, McGREGOR JL and RAUTENBACH CJ DEW (2007) On the development of a new nonhydrostatic atmospheric model in South Africa. S. Afr. J. Sci. 103 127-134.

ENGELBRECHT FA, McGREGOR JL and ENGELBRECHT CJ (2009) Dynamics of the conformal-cubic atmospheric model projected climate-change signal over southern Africa. Int. J. Climatol. 29 1013-1033. DOI: 10/1002/joc.1742.29. 1013-1033.

GATES WL (1992) AMIP: The atmospheric model intercomparison project. Bull. Am. Meteorol. Soc. 73 1962-1970.

GHILE YB and SCHULZE RE (2009) Evaluation of three numerical weather prediction models for short and medium range agrihydrology applications. Water Resour. Manage. 24 1005-1028.

HOLTSLAG AAM and BOVILLE BA (1993) Local versus non-local boundary layer diffusion in a global climate model. J. Clim. 6 1825-1842.

JANJIC ZI, GERRITY JP (Jr) and NICKOVIC S (2001) An alternative approach to nonhydrostatic modeling. Mon. Weather Rev. 129 1164-1178.

JONES GV, DUFF AA, HALL A and MYERS JW (2010) Spatial analysis of climate in winegrape growing regions in the western United States. Am. J. Enol. Vitic. 61 (3) 313-326.

JURY MR (1996) Regional teleconnection patterns associated with summer rainfall over South Africa, Namibia and Botswana. Int. J. Climatol. 16 135-153.

JURY MR, MULENGA HM and MASON SJ (1999) Exploratory long-range models to estimate summer climate variability over southern Africa. J. Clim. 12 1892-1899.

KALNAY E, KANAMITSU M, KISTLER R, COLLINS W, DEAVEN D, GANDIN L, IREDELL M, SAHA S, WHITE G, WOOLLEN J, ZHU Y, CHELLIAH M, EBISUZAKI W, HIGGINS W, JANOWIAK J, MO KC, ROPELEWSKI C, WANG J, LEETMAA A, REYNOLDS R, JENNE R and JOSEPH D (1996) The NCEP/NCAR 40-year reanalysis project. Bull. Am. Meteorol. Soc. 77 437-472.

KATZFEY JJ, McGREGOR JL, NGUYEN KC and THATCHER M (2009) Dynamical downscaling techniques: Impacts on regional climate change signals. In: Anderssen RS, Braddock RD and Newham LTH (eds.) MODSIM09 Int. Congress on Modelling and Simulation. URL: www.mssanz.org.au/modsim09/I13/katzfey_ I13.pdf. 2377-2383.

KLOPPER E, LANDMAN WA and VAN HEERDEN J (1998) The predictability of seasonal maximum temperature in South Africa. Int. J. Climatol. 18 741-758.

KOWALCZYK E A, GARRATT JR and KRUMMEL PB (1994) Implementation of a soil-canopy scheme into the CSIRO GCM -regional aspects of the model response. CSIRO Div. Atmospheric Research Tech. Paper No. 32. 59 pp.

LACIS AA and HANSEN JE (1974) A parameterization for the absorption of solar radiation in the earth's atmosphere. J. Atmos. Sci. 31 118-133. DOI:10.1175/1520-0469(1974)031<0118:APFTAO $>2.0 . \mathrm{CO} ; 2$.

LAL M, McGREGOR JL and NGUYEN KC (2008) Very highresolution climate simulations over Fiji using a global variableresolution model. Clim. Dyn. 30 293-305.

LANDMAN S, ENGELBRECHT FA, ENGELBRECHT CJ, LANDMAN WA, DYSON L (2010a) A multi-model ensemble system for short-range weather prediction in South Africa. Proc. $26^{\text {th }}$ Annual Conference of the South African Society for Atmospheric Sciences. September 2010, Gariep Dam, South Africa. ISBN: 978-0-620-47333-0.

LANDMAN WA and BERAKI A (2010) Multi-model forecast skill for mid-summer rainfall over southern Africa. Int. J. Climatol. DOI: $10.1002 /$ joc. 2273 .

LANDMAN WA and GODDARD L (2002) Statistical recalibration of GCM forecast over southern Africa using model output statistics. J. Clim. 15 2038-2055.

LANDMAN WA and MASON SJ (1999) Operational long-lead prediction of South African rainfall using canonical correlation analysis. Int. J. Climatol. 19 1073-1090.

LANDMAN WA, DEWITT D, LEE D-E, BERAKI A and LÖTTER D (2011) Seasonal rainfall prediction skill over South Africa: 1vs. 2-tiered forecasting systems. Weather Forecast. DOI: 10.1175/ WAF-D-11-00078.1.

LANDMAN WA, ENGELBRECHT FA, BERAKI A, ENGELBRECHT C, MBEDZ M, GILL T and NTSANGWANE L (2009) Model Output Statistics Applied to Multi-Model Ensemble LongRange Forecasts over South Africa. WRC Report No. 1492/1/08. Water Research Commission, Pretoria, South Africa. 56 pp.

LANDMAN WA, ENGELBRECHT F, PARK R, BOPAPE M and LOTTER D (2010b) Atmospheric modelling and prediction at time-scales from days to seasons. Proc. CSIR Biannual Conference, August/September 2010, Pretoria, South Africa. Reference NE05-P0-F.

LE ROUX N (2009) Seasonal Maize Yield Simulations for South Africa Using a Multi-Model Ensemble System. M.Sc. thesis. University of Pretoria, Pretoria, South Africa. 152 pp.

MASON SJ (1998) Seasonal forecasting of South African rainfall using a non-linear discriminant analysis model. Int. J. Climatol. 18 147-164.

MASON SJ and JOUBERT AM (1997) Simulated changes in extreme rainfall over southern Africa. Int. J. Climatol. 17 291-301.

McGREGOR JL, GORDON HB, WATTERSON IG, DIX MR and ROTSTAYN LD (1993) The CSIRO 9-level atmospheric general circulation model. CSIRO Div. Atmospheric Research Tech. Paper No. 26. 89 pp.

McGREGOR JL (1996) Semi-Lagrangian advection on conformalcubic grids. Mon. Weather Rev. 124 1311-1322.

McGREGOR JL (2003) A new convection scheme using a simple closure. In: Current Issues in the Parameterization of Convection. BMRC Research Report 93. 33-36.

McGREGOR JL (2005a) Geostrophic adjustment for reversibly staggered grids. Mon. Weather Rev. 133 1119-1128.

McGREGOR JL (2005b) C-CAM: Geometric aspects and dynamical formulation. CSIRO Atmospheric Research Tech. Paper No. 70. 43 pp.

McGREGOR JL and DIX MR (2001) The CSIRO conformal-cubic atmospheric GCM. In: Hodnett PF (ed.) Proc. IUTAM Symposium on Advances in Mathematical Modelling of Atmosphere and Ocean Dynamics. Kluwer, Dordrecht. 197-202.

McGREGOR JL and DIX MR (2008) An updated description of the Conformal-Cubic Atmospheric Model. In: Hamilton K and Ohfuchi W (eds.) High Resolution Simulation of the Atmosphere and Ocean. Springer Verlag. 51-76.

McGREGOR JL, KATZFEY JJ, NGUYEN KC and THATCHER MJ (2011) Some recent developments for dynamical downscaling of climate. Proc. 27th Annual Conference of the South African Society for Atmospheric Sciences. September 2011 Hartebeeshoek.

MITCHELL TD and JONES PD (2005) An improved method of constructing a database of monthly climate observations and associated high-resolution grids. Int. J. Climatol. 25 693-712.

OLWOCH JM, REYERS B, ENGELBRECHT FA and ERASMUS BFN (2008) Climate change and the tick-borne disease, theileriosis (East Coast Fever) in sub-Saharan Africa. J. Arid Environ. 72 108-120.

POTGIETER CJ (2006) Accuracy and skill of the conformal-cubic atmospheric model in short-range weather forecasting over southern Africa. M.Sc. Thesis, University of Pretoria. 172 pp.

POTGIETER C (2009) Cut-Off Low Characteristics over South Africa in the Future Climate. ARC Technical Report No. GW/A/2009/26. Project GW/050/054. Agricultural Research Council, Pretoria, South Africa.

REASON CJC and ROUAULT M (2005) Links between the antarctic oscillation and winter rainfall over western South Africa. Geophys. Res. Lett. 32 L07705. DOI:10.1029/2005GL022419.

ROUX B (2009) Ultra High-Resolution Climate Simulations over the Stellenbosch Wine-Producing Region using a Variable-Resolution Model. M.Sc. Thesis. University of Pretoria, Pretoria, South Africa. 96 pp. 
ROTSTAYN LD (1997) A physically based scheme for the treatment of stratiform clouds and precipitation in large-scale models. I: Description and evaluation of the microphysical processes. Quart. J. R. Meteorol. Soc. 123 1227-1282.

SCHWARZKOPF MD and FELS SB (1991) The simplified exchange method revisited: an accurate, rapid method for computation of infrared cooling rates and fluxes. J. Geophys. Res. 96 9075-9096.

TENNANT WJ and HEWITSON B (2002) Intra-seasonal rainfall characteristics and their importance to the seasonal prediction problem. Int. J. Climatol. 22 1033-1048.
THATCHER M and McGREGOR JL (2009) Using a scale-selective filter for dynamical downscaling with the conformal cubic atmospheric model. Mon. Weather Rev. 137 1742-1752.

THATCHER M and McGREGOR JL (2010) A technique for dynamically downscaling daily-averaged GCM datasets over Australia using the Conformal Cubic Atmospheric Model. Mon. Weather Rev. 139 79-95.

WILKS DS (2006) Statistical Methods in the Atmospheric Sciences ( $2^{\text {nd }}$ edn.). Academic Press, Burlington. 627 pp. 